\title{
EFFECT OF SAMPLE AND GRAIN SIZE ON THE COMPRESSIVE STRENGTH OF ICE
}

\author{
Stephen J. Jones and H. A. M. Chew
}

(National Hydrology Research Institute, Environment Canada, Ottawa, Ontario K1A OE7, Canada)

\begin{abstract}
The effect of sample and grain size on the uniaxial compressive strength of polycrystalline ice has been investigated at $-10^{\circ} \mathrm{C}$, at a strain-rate of $5.5 \times 10^{-4} \mathrm{~s}^{-1}$. The results show (a) that the sample size must be 12 or more times greater than the grain size for it to have no effect on the strength and (b) that there is no significant dependence of compressive strength on grain size, within the grainsize range of 0.6 to $2.0 \mathrm{~mm}$.
\end{abstract}

\section{INTRODUCTION}

Two of the possible variables that might affect the strength of polycrystalline ice, as determined in laboratory experiments, are the size of the sample being tested, and the size of the individual grains in the sample. We report here tests done at $-10^{\circ} \mathrm{C}$ in uniaxial compression, at a strain-rate of

$5.5 \times 10^{-4} \mathrm{~s}^{-1}$, to investigate these effects.

The effect of grain size is of particular importance because of conflicting results in the literature. Muguruma (1969) found that the maximum stress for columnar-grained ice varied linearly with the inverse square root of the grain diameter, within the grainsize range from 2 to $5 \mathrm{~mm}$. However, Bromer and Kingery (1968) found that the viscosity of columnar-grained ice was proportional to the grain size squared. Baker (1978) found a more complicated relationship in that the creep rate $\varepsilon$ was related to grain size d by $\varepsilon \propto d^{N}$ where $\mathrm{N}=-2.35$ for $\mathrm{d}<1.0 \mathrm{~mm}$ and $\mathrm{N}=+2.5$ for d $>1.0 \mathrm{~mm}$. Duval and LeGac (1980), however, found that the creep rate was independent of crystal size. We, therefore, thought that it would be worthwhile to try and settle this matter by testing many samples at one temperature and one strain-rate.

Preliminary results have been published in Jones and Chew (1981).

\section{SAMPLE PREPARATION}

The polycrystalline samples were prepared by freezing deaerated water, under vacuum, in molds using sieved snow, or crushed ice, as a 'seed'. By varying the size of the sieve for the snow, ice samples of different grain size were made. As grown, the samples were approximately $50 \mathrm{~mm}$ in diameter and $200 \mathrm{~mm}$ long. They sometimes contained a few air bubbles running down the central core of the sample, but, by cutting the sample into four sections and machining, air-free samples of diameter $20 \mathrm{~mm}$ were obtained. When the grain size was larger than $1.6 \mathrm{~mm}$, however, the sample diameter was increased to $34 \mathrm{~mm}$.
The length to diameter ratio of the sample was constant at about 3.0. End caps made of stainless steel were frozen onto the samples. Thin sections were cut and examined under crossed polaroids to determine grain size. The grain size was determined by counting the number of grains in $1 \mathrm{~cm}^{2}$ of a thin section and then calculating an average diameter assuming circular grains.

\section{EXPERIMENTAL METHOD}

The mechanical testing was done on a standard Instron model 1116, which is a screw-driven, $25000 \mathrm{~kg}$ capacity machine. They were done at a constant speed of deformation but not strictly at a

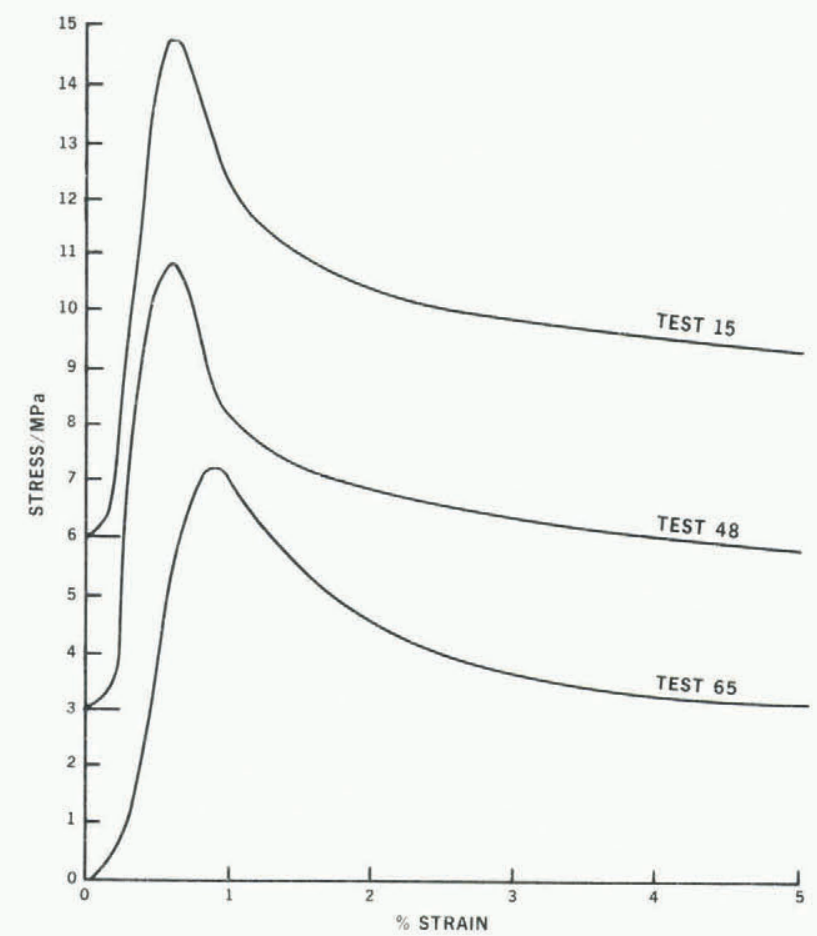

Fig.1. Three typical stress/strain curves for polycrystalline ice deformed in compression at $-10^{\circ} \mathrm{C}$ at a strain-rate of $5.5 \times 10^{-4} \mathrm{~s}^{-1}$. Note the change in origin on the ordinate (stress) to avoid overlapping curves. 
constant strain-rate. To prevent evaporation, all samples were immersed in silicon oil inside a heavy steel vessel, and were left overnight to reach temperature equilibrium. The steel vessel was inside a cold chamber placed on the Instron, the Instron $i$ tself being kept at normal room temperature. The temperature of the sample was measured with a thermocouple placed in the silicon oil close to the sample. During a given test the temperature was constant to within $0.1^{\circ} \mathrm{C}$, and the mean temperature for all 62 tests was $-10.0 \pm 0.5^{\circ} \mathrm{C}$.

A nominal strain-rate of $5.5 \times 10^{-4} \mathrm{~s}^{-1}$ was used throughout. The load was measured by means of a load cell in the Instron crosshead beam. The sample compression was not measured directly, but was calculated from the speed of crosshead motion and the elapsed time. For each test a load/compression curve was recorded on a chart recorder. The load was converted to stress by dividing by the initial crosssectional area and the compression was converted to strain by dividing by the initial length of the sample.

\section{RESULTS}

Three typical stress/strain curves are shown in Figure 1. Initially the stress rose rapidly and almost linearly to a peak or maximum stress. It is this peak (or maximum stress) that we took as the strength of the ice. After the peak, the stress dropped as the ice deformed plastically until the tests were ended at a strain of about $7 \%$. After such a strain the samples contained many cracks, particularly in the bulged-out, centre section which was

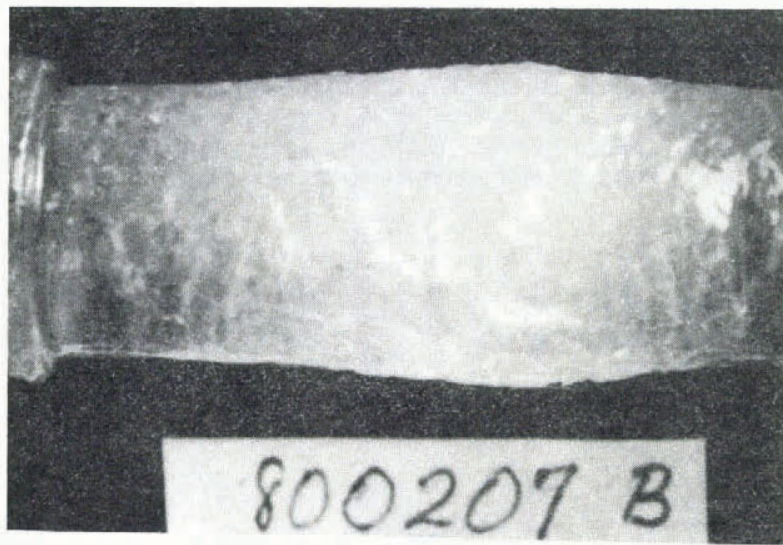

Fig.2. A typical sample after a uniaxial compression of $7 \%$, deformed at $-10^{\circ} \mathrm{C}$ and $5.5 \times 10^{-4} \mathrm{~s}^{-1}$.

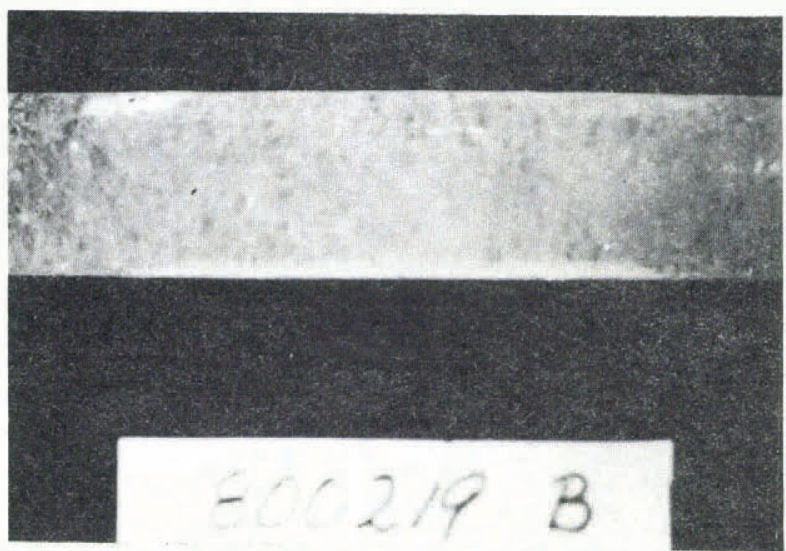

Fig.3. A typical sample observed just after the maximum stress or strength was reached. Total strain $1.5 \%,-10^{\circ} \mathrm{C}, 5.5 \times 10^{-4} \mathrm{~s}^{-1}$. There are fewer cracks than in Figure 2, taken after $7 \%$ strain. more deformed than the end regions, as shown in Figure 2. However, some samples were observed immediately after the maximum stress. They contained a few cracks, as shown in Figure 3. Table I lists all the tests carried out.

Our first experiment was to examine how the strength, or maximum stress, varied with the ratio of sample/grain size. For this, the grain size was kept constant at $1 \mathrm{~mm}$ and the sample diameter varied. The results are given in Figure 4 , which shows that the ratio of sample size to grain size must be greater than about 12 for there to be no effect of this ratio on the strength.

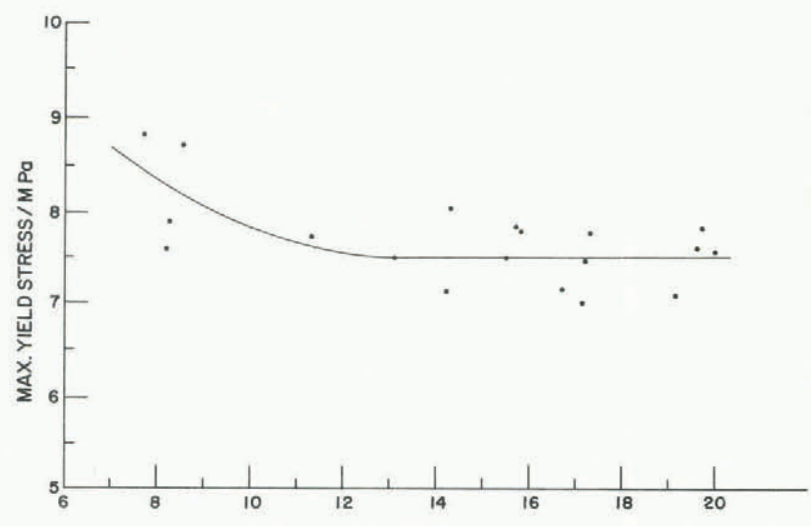

RATIO SAMPLE SIZE / GRAIN SIZE

Fig.4. The maximum yield stress plotted against the ratio of sample size to grain size. The grain size was kept constant at $1.0 \mathrm{~mm}$ and the sample diameter was varied. Below a ratio of 12 the maximum stress depends on this ratio.

Bearing this in mind, we then investigated the effect of grain size on the maximum yield stress. Figure 5 shows the results of the 62 tests, which give a mean strength of $7.5 \pm 0.6 \mathrm{MPa}$. While there is some scatter in the data, there is no significant trend or dependence of strength on grain diameter, within the size range shown.

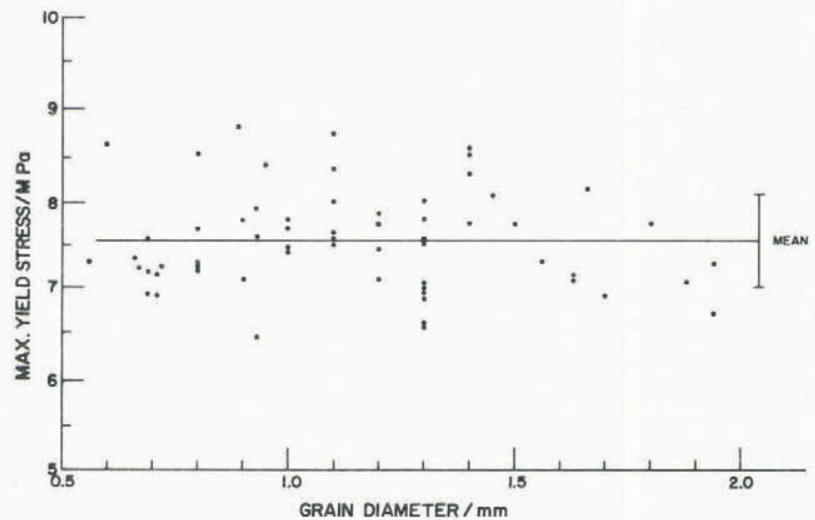

Fig.5. The maximum stress, or strength, plotted against grain size, for laboratory-grown polycrystalline ice tested at $-10^{\circ} \mathrm{C}$.

\section{SCUSSION}

The question of the sample/grain size ratio has been discussed in the literature for some years. Hawkes and Mellor (1970) have suggested a lower limit of 10 for general rock testing, and have used a much larger ratio, 36, for their work on ice (Hawkes and Mellor 1972). However, the present work is the first experimental evidence for ice in favour of keeping this ratio greater than about 12 . 
TABLE I. SUMMARY OF ALL THE STRESS/STRAIN RESULTS OBTAINED IN THIS STUDY

\begin{tabular}{|c|c|c|c|c|c|c|}
\hline Test no. & Peak stress & Grain size & Peak strain & $\begin{array}{l}\text { Strain at } \\
\text { end of } \\
\text { test } \\
(\%)\end{array}$ & $\begin{array}{l}\text { Stress at } \\
\text { end of } \\
\text { test } \\
(\mathrm{MPa})\end{array}$ & $\begin{array}{c}\text { Time } \\
\text { to } \\
\text { peak } \\
\text { (s) }\end{array}$ \\
\hline 2 & 7.64 & 1.13 & 1.23 & 7.03 & 3.00 & 22 \\
\hline 3 & 7.06 & 1.30 & 0.79 & 7.78 & 2.90 & 14 \\
\hline 4 & 7.00 & 1.30 & 0.79 & 3.67 & 3.66 & 14 \\
\hline 5 & 6.98 & 1.30 & 0.79 & 5.72 & 3.25 & 14 \\
\hline 10 & 6.88 & 1.30 & 1.50 & 8.55 & 3.36 & 27 \\
\hline 12 & 6.56 & 1.30 & 1.19 & 8.55 & 3.69 & 22 \\
\hline 13 & 6.94 & 1.30 & 0.96 & 7.79 & 3.38 & 17 \\
\hline 15 & 8.76 & 1.10 & 0.62 & 11.29 & 3.00 & 11 \\
\hline 18 & 7.46 & 1.20 & 0.39 & 1.73 & 5.09 & 7 \\
\hline 25 & 7.11 & 0.90 & 0.99 & 5.54 & 3.40 & 18 \\
\hline 26 & 7.49 & 1.00 & 0.59 & 3.22 & 3.62 & 11 \\
\hline 27 & 7.79 & 0.90 & 0.56 & 2.01 & 4.27 & 10 \\
\hline 28 & 7.47 & 1.00 & 0.69 & 3.40 & 3.38 & 12 \\
\hline 29 & 7.88 & 1.20 & 0.56 & 1.67 & 4.58 & 10 \\
\hline 30 & 7.66 & 1.20 & 0.69 & 2.69 & 3.99 & 12 \\
\hline 31 & 7.57 & 1.30 & 0.66 & 3.18 & 3.59 & 12 \\
\hline 32 & 8.03 & 1.30 & 0.69 & 2.69 & 3.90 & 13 \\
\hline 33 & 7.75 & 1.50 & 0.59 & 2.89 & 3.62 & 11 \\
\hline 34 & 8.53 & 1.40 & 0.66 & 3.39 & 3.72 & 12 \\
\hline 35 & 6.91 & 1.70 & 0.66 & 2.69 & 3.59 & 12 \\
\hline 36 & 6.59 & 1.30 & 0.79 & 2.69 & 3.52 & 14 \\
\hline 37 & 7.11 & 1.20 & 0.59 & 2.28 & 3.95 & 11 \\
\hline 38 & 7.02 & 1.30 & 0.56 & 3.04 & 3.61 & 10 \\
\hline 39 & 7.79 & 1.30 & 0.49 & 3.18 & 3.41 & 9 \\
\hline 40 & 8.32 & 1.40 & 0.56 & 3.28 & 3.27 & 10 \\
\hline 41 & 7.75 & 1.80 & 0.59 & 3.39 & 3.52 & 11 \\
\hline 42 & 7.60 & 1.10 & 0.69 & 4.34 & 3.30 & 12 \\
\hline 43 & 7.43 & 1.00 & 0.49 & 10.30 & 2.74 & 9 \\
\hline 44 & 7.71 & 1.00 & 0.61 & 11.50 & 2.90 & 11 \\
\hline 45 & 7.78 & 1.00 & 0.61 & 9.53 & 2.62 & 11 \\
\hline 46 & 8.43 & 0.95 & 0.54 & 7.02 & 3.52 & 10 \\
\hline 47 & 8.58 & 1.40 & 0.54 & 6.46 & 2.42 & 10 \\
\hline 48 & 7.75 & 1.40 & 0.54 & 5.63 & 2.69 & 10 \\
\hline 49 & 8.82 & 0.89 & 0.71 & 6.46 & 4.71 & 13 \\
\hline 50 & 7.24 & 0.80 & 0.88 & 7.02 & 3.62 & 16 \\
\hline 51 & 7.25 & 0.80 & 0.61 & 5.54 & 3.72 & 11 \\
\hline 52 & 8.56 & 0.80 & 0.66 & 6.46 & 3.37 & 12 \\
\hline 53 & 7.70 & 0.80 & 0.61 & 5.73 & 3.51 & 11 \\
\hline 54 & 8.02 & 1.10 & 0.54 & 5.18 & 3.62 & 10 \\
\hline 55 & 8.38 & 1.10 & 0.54 & 4.82 & 3.66 & 10 \\
\hline 56 & 7.94 & 0.93 & 0.54 & 6.46 & 3.53 & 10 \\
\hline 57 & 7.59 & 0.93 & 0.61 & 6.28 & 3.62 & 11 \\
\hline 58 & 6.45 & 0.93 & 1.04 & 6.46 & 3.61 & 19 \\
\hline 59 & 7.26 & 9.72 & 0.86 & 10.70 & 3.87 & 16 \\
\hline 60 & 7.15 & 0.71 & 0.66 & 8.69 & 3.31 & 12 \\
\hline 61 & 6.91 & 0.71 & 0.87 & 12.53 & 4.48 & 16 \\
\hline 62 & 7.29 & 0.80 & 0.54 & 9.07 & 3.56 & 10 \\
\hline 63 & 6.52 & 1.94 & 0.60 & 8.68 & 2.49 & 17 \\
\hline 64 & 7.08 & 1.63 & 0.62 & 7.71 & 2.60 & 18 \\
\hline 65 & 7.28 & 0.67 & 0.88 & 15.75 & 2.73 & 12 \\
\hline 67 & 7.06 & 1.88 & 1.06 & 11.22 & 2.65 & 22 \\
\hline 68 & 7.15 & 1.63 & 0.62 & 8.60 & 2.63 & 12 \\
\hline 69 & 8.07 & 1.45 & 0.53 & 5.16 & 2.92 & 10 \\
\hline 70 & 7.28 & 1.94 & 1.04 & 10.14 & 2.73 & 20 \\
\hline 71 & 7.29 & 1.56 & 0.98 & 6.71 & 2.34 & 20 \\
\hline 72 & 8.15 & 1.66 & 0.65 & 10.77 & 3.22 & 12 \\
\hline 73 & 6.92 & 0.69 & 0.88 & 8.30 & 3.66 & 16 \\
\hline 74 & 7.20 & 0.69 & 0.99 & 8.30 & 3.56 & 16 \\
\hline 75 & 7.58 & 0.69 & 0.74 & 7.27 & 3.99 & 14 \\
\hline 76 & 7.36 & 0.66 & 0.66 & 7.60 & 2.90 & 12 \\
\hline 79 & 7.30 & 0.56 & 0.99 & 12.88 & 4.74 & 18 \\
\hline 80 & 8.65 & 0.60 & 0.55 & 10.97 & 4.60 & 10 \\
\hline
\end{tabular}


It is a little surprising that the strength of ice increases when the sample/grain size ratio is reduced below about 12 . When this ratio tends to 1 a single crystal results, and, in general, the strength of a single ice crystal is much less than a polycrystal. So at some value of sample/grain size ratio less than 8 (our lowest value) and greater than 1 the strength probably does reach a maximum and then decreases to the single crystal value, due to the increased ductility of single crystals. The increase in strength for ratios $\leqslant 12$ is probably due to there being fewer grain boundaries and hence less chance of crack formation.

We have shown that grain size has no effect on the compressive strength of ice, within the grainsize range from 0.6 to $2.0 \mathrm{~mm}$. This is in agreement with the creep results of Duval and LeGac (1980), but in apparent disagreement with Muguruma (1969), Bromer and Kingery (1968), Baker (1978), and most recently Currier and Schulson (1982). However, Muguruma's samples were small compared to his columnar grain size, a fact which must have influenced his results; Bromer and Kingery (1968) also used small samples and such small stress and test times that they were almost certainly not measuring a secondary creep rate; Baker (1978) also may not have always been measuring a secondary creep rate, since his test times varied considerably, the start time for beginning of run varying from 34 to $449 \mathrm{~h}$. This means his measurements must have been taken at very different strains. Unfortunately his paper gives no creep curves so it is difficult to be more definite as to the cause of the disagreement between his work and ours.

Currier and Schulson (1982) have recently presented results on the tensile strength of ice, which show a classical Hall-Petch relationship, $\sigma \propto \mathrm{d}^{-1 / 2}$, between strength $\sigma$ and grain size d for a wide range of grain sizes from 1 to $7 \mathrm{~mm}$. The results are reproducible and large samples were used. The fact that they observed tensile strengths of about $1.0 \mathrm{MPa}$ as opposed to our compressive strengths of $7.5 \mathrm{MPa}$ under otherwise similar conditions, indicates that we are not looking at the same physical phenomenon. Currier and Schulson (1982) believe that their tensile strength is controlled by the propagation, in a brittle manner, of microcracks nucleated through dislocation pile-ups at grain boundaries. This leads to fracture at the much lower stresses than we observed. We have a more complicated situation where the sample is both deforming and cracking at the same time. However, since we know that the application of hydrostatic pressure suppresses cracking and allows the stress to rise much higher before yielding occurs (Jones 1982), it is clearly the propagation of cracks which is controlling the stress level. Despite all the cracks, however, the sample does not fail completely but continues to support a decreasing load to the maximum strain used in these experiments of $7 \%$.

The agreement of our results with Duval and LeGac (1980) is, therefore, somewhat fortuitous because their experiments were done in creep at strain-rates where cracking did not occur.

\section{CONCLUSIONS}

Sample sizes must be greater than 12 times the grain size for tests to give compressive strength results independent of sample size.

The uniaxial compressive strength of ice is independent of grain size, at a strain-rate of $5.5 \times 10^{-4} \mathrm{~s}^{-1}$ and $-10^{\circ} \mathrm{C}$. Crack formation governs the stress level reached but samples continue to deform to strains of several per cent before failure occurs.

\section{REFERENCES}

Baker R W 1978 The influence of ice-crystal size on creep. Joumal of Glaciology 21(85): 485-500

Bromer D J, Kingery W D 1968 Flow of polycrystalline ice at low stresses and small strains. Journal of Applied Physics 39(3): 1688-1691
Currier J H, Schulson E M 1982 The tensile strength of ice as a function of grain size. Acta Metallurgica 30(8): 1511-1514 (Abstract in Annals of Glaciology 1983 4: 305)

Duval P, Le Gac H 1980 Does the permanent creeprate of polycrystalline ice increase with crystal size? Joumal of Glaciology 25(91): 151-157

Hawkes I, Mellor H 1970 Uniaxial testing in rock mechanics laboratories. Engineering Geology 4(3): $177-285$

Hawkes I, Mellor H 1972 Deformation and fracture of ice under uniaxial stress. Joumal of Glaciology 11(61): 103-131

Jones S J 1982 The confined compressive strength of polycrystalline ice. Joumal of Glaciology 28(98): 171-177

Jones S J, Chew H A M 1981 On the grain-size dependence of secondary creep. Journal of Glaciology $27(97)$ : $517-518$

Muguruma J 1969 Effects of surface condition on the mechanical properties of ice crystals. British Joumal of Applied Physics Ser 2, 2: 1517-1525 